\title{
Germinação in vitro e desenvolvimento pós-seminal de plântulas de Pilosocereus aurisetus (Werderm.) Byles \& G.D. Rowley (Cactaceae)
}

\author{
Michele Valquíria dos Reis ${ }^{1}$, Rogério Gomes Pêgo², Patrícia Duarte de Oliveira Paiva ${ }^{3}$, \\ Fabiane Aparecida Artioli-Coelho ${ }^{4}$, Renato Paiva ${ }^{5}$
}

\begin{abstract}
RESUMO
Pilosocereus aurisetus é uma espécie de cactos de importância econômica e ambiental que se encontra em risco de extinção. A propagação em áreas naturais ocorre, principalmente, de forma sexuada; entretanto, não há registro da germinação e viabilidade de sementes e morfologia pós-seminal de plântulas dessa espécie. Assim, objetivou-se avaliar a germinação de sementes e descrever a morfologia do desenvolvimento pós-seminal de plântulas de P. aurisetus. Para isso, sementes, armazenadas em condições ambientais por 19 meses, foram submetidas aos tratamentos: embebição

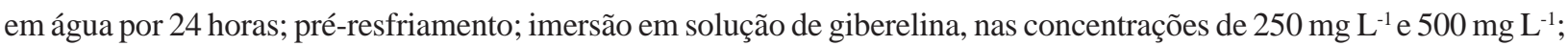
e um tratamento controle. As sementes foram colocadas para germinar em meio de cultura MS, por 30 dias, quando se avaliou a percentagem de germinação. O delineamento estatístico foi o inteiramente casualizado, com cinco tratamentos e quatro repetições, sendo dispostas 25 sementes por parcela. A caracterização pós-seminal foi realizada por um período de 60 dias, utilizando-se microscópio binocular, com base nas Regras para Análise de Sementes. Maior percentagem da germinação de sementes ocorreu no controle, ou quando embebidas por 24 horas, sendo observados $90 \%$ e $83 \%$, respectivamente. A morfologia do desenvolvimento pós-seminal indicou que a germinação é do tipo epígea, com hipocótilo de reserva; suas plântulas sofrem modificações na região do colo, para a emissão de raízes, e apresentam cerdas no ápice caulinar, mesmo na fase inicial da expansão cotiledonar. A diferenciação e início da formação das costelas iniciam-se aos 60 dias após a germinação, com o desenvolvimento do epicótilo.
\end{abstract}

Palavras-chave: morfologia, armazenamento, extinção, giberelina.

\section{ABSTRACT \\ In vitro germination and post-seminal development of plantlets of Pilosocereus aurisetus (Werderm.) Byles \& G.D. Rowley (Cactaceae)}

Pilosocereus aurisetus is a species of cactus of economic and environmental importance, but the predatory exploitation led the species to be listed as threatened with extinction. $P$. aurisetus propagation occurs mainly in natural environment by sexual reproduction, though there is no record of germination, viability and morphology of postseminal seeds of this species. Thus, the objective of this study was to evaluate the germination and describe the morphology of post-seminal development of seeds of $P$. aurisetus. For this purpose, seeds stored at ambient conditions for 19 months were treated as follows: soaking in water for 24 hours, pre-cooling, soaking in solution of gibberellin in concentrations of $250 \mathrm{mg} \mathrm{L}^{-1}$ and $500 \mathrm{mg} \mathrm{L}^{-1}$ and a control. The seeds were germinated on MS medium for 30 days, when

Recebido para publicação em 04/03/2011 e aprovado em 14/11/2012

'Engenheira-Agrônoma, Mestre. Doutoranda do Departamento de Biologia, Universidade Federal de Lavras, Caixa Postal 3037, 37200-000, Lavras, Minas Gerais, Brasil. mvreis@yahoo.com.br (autora para correspondência).

${ }^{2}$ Engenheiro-Agrônomo, Mestre. Doutorando do Departamento de Fitotecnia, Universidade Federal de Viçosa, Campus Viçosa, Avenida Peter Henry Rolfs, s/n, 36570-000, Viçosa, Minas Gerais, Brasil. engagopego@yahoo.com.br

${ }^{3}$ Engenheira-Agrônoma, Doutora. Departamento de Agricultura, Universidade Federal de Lavras, Caixa Postal 3037, 37200-000, Lavras, Minas Gerais, Brasil. patriciapaiva@dag.ufla.br ${ }^{4}$ Bióloga, Mestre. Doutoranda do Departamento de Biologia, Escola Superior de Agricultura "Luiz de Queiroz" - USP, Avenida Pádua Dias, 11, 13418-900, Piracicaba, São Paulo, Brasil. fabiane_art@yahoo.com.br

${ }^{5}$ Engenheiro-Agrônomo, PhD. Departamento de Biologia, Universidade Federal de Lavras, Caixa Postal 3037, 37200-000, Lavras, Minas Gerais, Brasil. renpaiva@dbi.ufla.br 
the germination percentage was evaluated. The statistical design was completely randomized with five treatments and four replications with 25 seeds per plot. The post-seminal characterization was performed for a period of 60 days using a stereomicroscope based on the International Rules for Testing Seeds. A higher percentage of germination was observed in the control or when soaked for 24 hours, with $90 \%$ and $83 \%$ respectively. The morphology of the postseminal seeds indicated that the $P$. aurisetus germination is epigeous with reservation hypocotyl, seedlings changes lap region to emit roots and bristles present in shoot apex even in early stages of cotyledon expansion. The early differentiation and the formation of the ribs begin 60 days after germination with the development of the epicotyl.

Key words: Cactaceae, morphology, storage, extinction, gibberellin.

\section{INTRODUÇÃO}

A família Cactaceae apresenta mais de 125 gêneros em todo o mundo, sendo que, no Brasil, ocorrem 35 gêneros, em que estão compreendidas 237 espécies (Ortega-Baes \& Godínez-Alvarez, 2006). Nos campos rupestres da Serra do Espinhaço, que se estende pelos estados de Minas Gerais e Bahia, ocorrem várias espécies de cactos, destacando a Pilosocereus aurisetus, conhecida popularmente como quiabo-da-lapa, cujas plantas são exploradas de forma extrativista. Os caules dessa espécie são utilizados, principalmente, na composição de pratos típicos da culinária regional, e os frutos são consumidos in natura (Soffiatti \& Angyalossy, 2007). Essa atividade predatória não considera aspectos de preservação ecológica ou biologia da espécie, o que tem aumentado o risco de extinção (Ministério do Meio Ambiente, 2008).

Os cactos têm grande importância ecológica, pois seus caules e frutos são consumidos por pássaros, como Mimus saturninus e Cyanocorax caeruleus, larvas da mariposa Cactoblastis cactorum e marsupiais, como Didelphis aurita, dentre outros (Reyes-Aguero et al., 2006; Lenzi, 2008; Lessa et al., 2009). Ainda pode-se destacar sua importância comercial, quando utilizados como plantas ornamentais (Landgraf \& Paiva, 2009).

Como relatado em diversos estudos, a reprodução sexuada é a principal forma de propagação natural das cactáceas (Simão et al., 2007; Guillén et al., 2009; Quiala et al., 2009). Resende et al. (2010) trabalharam com propagação in vitro de Melocactus glaucescens, demonstrando que a cultura de tecidos é uma boa alternativa para a propagação de cactos.

As sementes de muitas espécies de cactos são predominantemente ortodoxas, podendo manter altas taxas de germinação após longos períodos de armazenamento. Algumas espécies podem aumentar a taxa de germinação, quando armazenadas em condições adequadas, mantendo-se viáveis por períodos de até 24 meses; após esse período, ainda são capazes de germinar e produzir plantas normais (Flores et al., 2008; Olvera-Carrilho et al., 2009).
Entretanto, não há relatos científicos sobre a viabilidade de sementes armazenadas e da caracterização pós-seminal de Pilosocereus aurisetus.

O conhecimento dos aspectos relacionados com a morfologia das sementes e das plântulas nos estádios iniciais de germinação é importante para estabelecer metodologias para adequar as condições de armazenamento de sementes, conservando a qualidade fisiológica, além de contribuir para a diferenciação de grupos taxonômicos e manutenção de bancos de germoplasma, sobretudo de espécies em risco de extinção (Melo \& Varela, 2006).

Graças à importância social, econômica e ecológica dessa espécie, é importante conhecer os aspectos relacionados com a sua propagação, para fins de preservação. Nesse sentido, o objetivo foi avaliar a germinação de sementes armazenadas de Pilosocereus aurisetus e descrever a morfologia pós-seminal de suas plântulas.

\section{MATERIAL E MÉTODOS}

Utilizaram-se sementes de Pilosocereus aurisetus, coletadas em áreas de ocorrência natural da Serra do Espinhaço, em Diamantina, Estado de Minas Gerais, as quais foram armazenadas em potes de plásticos, em temperatura ambiente, por um período de 19 meses, antes da condução do experimento.

Para se avaliar a germinação das sementes, foram testados cinco tratamentos pré-germinativos, como se segue: T1: embebição em água por 24 horas; T2: préresfriamento, a $10{ }^{\circ} \mathrm{C}$, por 24 horas; T3: imersão em giberelina $\left(\mathrm{GA}_{3}\right)$ a $250 \mathrm{mg} \mathrm{L}^{-1}$ por 1 minuto; T4: imersão em giberelina $\left(\mathrm{GA}_{3}\right)$ a $500 \mathrm{mg} \mathrm{L}^{-1}$, por 1 minuto; e T5: controle (sementes não tratadas). Após aplicação de cada tratamento, as sementes foram desinfestadas, em álcool etílico $70 \%$ (v/v), por 1 minuto e, em seguida, imersas em hipoclorito de sódio 2,5\% (v/v), por 10 minutos. Em câmara de fluxo laminar, as sementes foram lavadas três vezes, em água destilada autoclavada, sendo, posteriormente, inoculadas em meio MS (Murashige \& Skoog, 1962), acres- 
cido de $15 \mathrm{~g} \mathrm{~L}^{-1}$ de sacarose e solidificado com $8 \mathrm{~g} \mathrm{~L}^{-1}$ de ágar. $\mathrm{O} \mathrm{pH}$ do meio foi ajustado para 5,8 , antes da autoclavagem sob pressão de $1,5 \mathrm{~atm}$ e à temperatura de $120{ }^{\circ} \mathrm{C}$, por 20 minutos. Os frascos foram mantidos em sala de crescimento por 30 dias, sob irradiância de $43 \mu \mathrm{mol}$ $\mathrm{m}^{-2} \mathrm{~s}^{-1}$ e fotoperíodo de 16 horas, à temperatura de $25 \pm 2$ ${ }^{\circ} \mathrm{C}$. Aos 30 dias após a inoculação das sementes, calculou-se a percentagem de germinação.

Para a caracterização pós-seminal de plântulas, imagens digitais foram capturadas com câmera digital, acoplada a um microscópio estereoscópico binocular, com capacidade de aumento de 20 vezes, por um período de 60 dias. Os critérios estabelecidos para caracterização pós-seminal das plântulas foram semelhantes aos estabelecidos para Regra de Análise de Sementes (Brasil, 2009).

O delineamento estatístico foi o inteiramente casualizado, com cinco tratamentos e quatro repetições, sendo 25 sementes por parcela. Os dados foram submetidos à análise estatística e as médias comparadas pelo teste de Tukey, a 5\% de probabilidade.

\section{RESULTADOS E DISCUSSÃO}

Após o período de 19 meses, as sementes de $P$. aurisetus apresentaram $90 \%$ de germinação no tratamento controle (Figura 1), o que pode ser considerada alta percentagem, dado o longo período de armazenamento.

Normalmente, plantas nativas apresentam baixas percentagens de germinação, quando comparadas com espécies melhoradas, mas, quando se trata de sementes ortodoxas, muitas vezes a germinação é alta, mesmo após longos períodos de armazenamento (Rojas-Aréchiga \& Vázquez-Yanes, 2000; Nunes et al., 2008; Olvera-Carrilho et al., 2009).

Não houve diferença entre a taxa de germinação das sementes submetidas à embebição por 24 horas e a do controle, evidenciando que as sementes de $P$. aurisetus, embora possuam tegumento rígido, não apresentam dormência tegumentar, pois conseguem absorver a quantidade de água necessária para atingir uma percentagem de germinação satisfatória. Sementes de algumas espécies de cactáceas podem apresentar dormência quando colhidas, mas, quando armazenadas, essa dormência pode ser quebrada pela inativação de compostos inibitórios produzidos na região do funículo (Olvera-Carrillo et al., 2009).

O pré-resfriamento das sementes reduziu sua germinação para 38\% (Figura 1). Embora essa técnica seja frequentemente utilizada para aumentar a percentagem de germinação de várias espécies, como Eucomis autumnalis e Ottelia alismoides (Kulkarni et al, 2006; Yin et al., 2009), não é conhecido o efeito de tratamentos de préresfriamento de sementes de P. aurisetus. Normalmente, o pré-resfriamento pode substituir a aplicação de regulador de crescimento para quebra de dormência de sementes. Algumas cactáceas, como Maihuenia poeppigii, Cephalocereus chrysacanthus e Neobuxbaumia tetetzo necessitam de baixas temperaturas, entre 5 e $15^{\circ} \mathrm{C}$, para germinação das sementes (Rojas-Aréchiga \& VázquezYanes, 2000; Flores et al., 2008), fato esse que não foi observado em sementes de $P$. aurisetus.

A embebição de sementes em $\mathrm{GA}_{3}$ nas concentrações de $250 \mathrm{mg} \mathrm{L}^{-1}$ e $500 \mathrm{mg} \mathrm{L}^{-1}$, diminuiu a percentagem de germinação para 18\% e 13\%, respectivamente, possivelmente em resultado do efeito tóxico desse produto. As concentrações de giberelina utilizadas para germinação de cactos variam conforme a espécie, podendo ser encontrados relatos de efeito de doses que variam de $10 \mathrm{mg}$ $\mathrm{L}^{-1}$ a $2000 \mathrm{mg} \mathrm{L}^{-1}$, sendo a dose de $500 \mathrm{mg} \mathrm{L}^{-1}$ a mais comumente utilizada. No entanto, algumas espécies não apresentam aumento das taxas de germinação, quando tratadas com esse regulador (Rojas-Aréchiga et al., 2011).

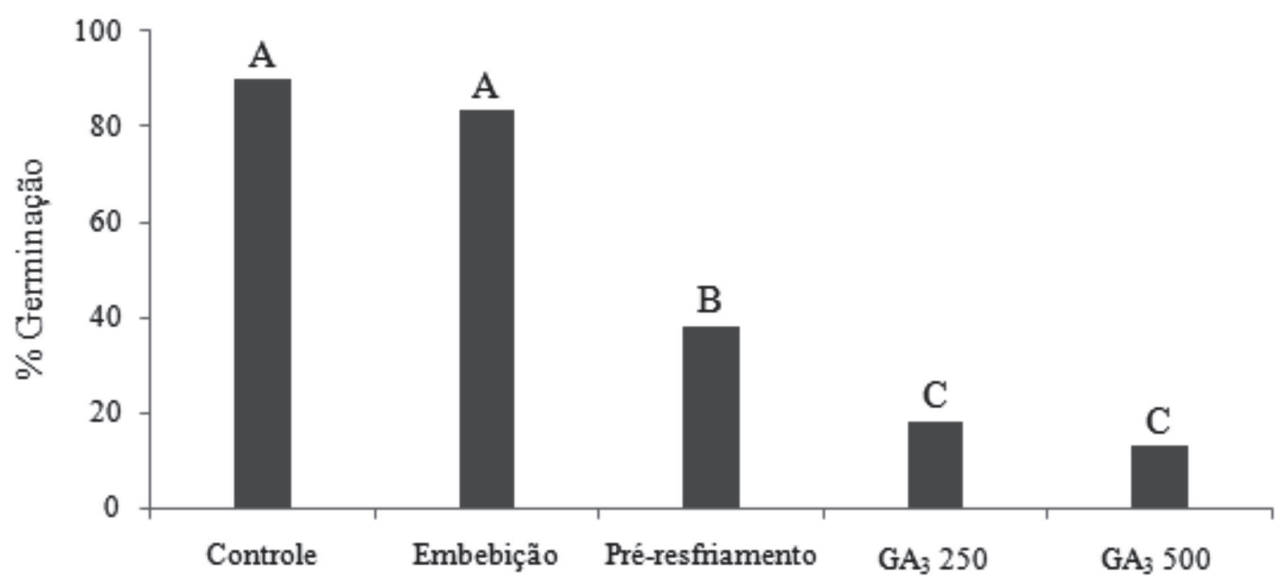

Figura 1. Germinação (\%) in vitro de sementes de Pilosocereus aurisetus armazenadas por 19 meses em diferentes tratamentos germinativos. Médias seguidas de mesma letra não diferem entre si, a 5\% de probabilidade pelo teste de Tukey. 
É possível que o armazenamento tenha causado a quebra da dormência das sementes e a presença de giberelina possa ter causado estresse e queda na germinação de sementes, como relatado para outras espécies de cactos, como em Opuntia tomentosa e Trichocereus terscheckii (Ortega-Baes \& Rojas-Aréchiga, 2007; Olvera-Carrillo et al., 2009). Olvera-Carrillo et al. (2003) não observaram a ação de $\mathrm{GA}_{3}$ sobre a germinação de $O$. tomentosa, quando aplicada isoladamente, sendo necessária a combinação desse produto com a escarificação física.

Sementes armazenadas por longos períodos podem-se apresentar viáveis, mas a qualidade fisiológica pode ser afetada, sendo que o condicionamento em ambientes com variações de temperatura ou a presença de componentes químicos, durante o processo de embebição, podem interferir na percentagem de germinação, o que pode ter ocorrido nos tratamentos com baixas temperaturas e giberelinas (Brasil, 2009). Essa pode ser uma característica adaptativa dessas plantas, pois as sementes dispersadas no campo podem não encontrar condições favoráveis à germinação, sendo necessário manter longevidade até que as condições ambientais favoreçam sua germinação e estabelecimento das plantas, como ocorre com muitas espécies de cactos (Flores et al., 2008; Rojas-Aréchiga et al., 2011).

A caracterização morfológica de sementes de $P$. aurisetus permitiu descrever as sementes dessa espécie como ovoides e lisas, com 1,2 a 1,5 mm de comprimento, sendo o tegumento rígido, de coloração preta e brilhante (Figura 2A). Na região mais angulada da semente, locali- za-se o hilo e, em algumas sementes, a polpa funicular mucilaginosa pode estar presente. Essas informações são importantes, pois características como coloração do tegumento, forma e cor do hilo possibilitam a diferenciação de espécies de cactáceas, mesmo quando pertencentes a um mesmo gênero (Arias \& Terrazas, 2004).

A germinação das sementes inicia-se após sete dias da inoculação em meio de cultura, caracterizada por uma abertura na região do hilo, permitindo o crescimento do eixo embrionário. A plântula apresenta-se inicialmente translúcida, mas, em poucas horas, torna-se esverdeada (Figura 2B). O hipocótilo apresenta-se robusto, resultante do embrião hipocotilar. Inicialmente, não há emissão de radículas, ou de pelos radiculares, mas é possível visualizar o ápice radicular diferenciado. A germinação pode ser caracterizada como epígea, com hipocótilo de reserva, pois a nutrição inicial da plântula é realizada pelo hipocótilo, uma vez que os cotilédones apresentam-se rudimentares, como é característico de outras espécies de cactos (Bregman \& Bouman, 1983).

É possível observar um entumescimento da região terminal basal da plântula, resultante de divisões celulares para a diferenciação e emissão de radículas (Figura 2C). O início da rizogênese causa um estreitamento do colo da planta, possivelmente pela degradação e alocação de reservas para o crescimento radicular. Ainda é possível observar o desenvolvimento normal das raízes (Figura 2D). Normalmente, o alongamento das plântulas é maior após três a quatro dias do início da germinação, perdendo os
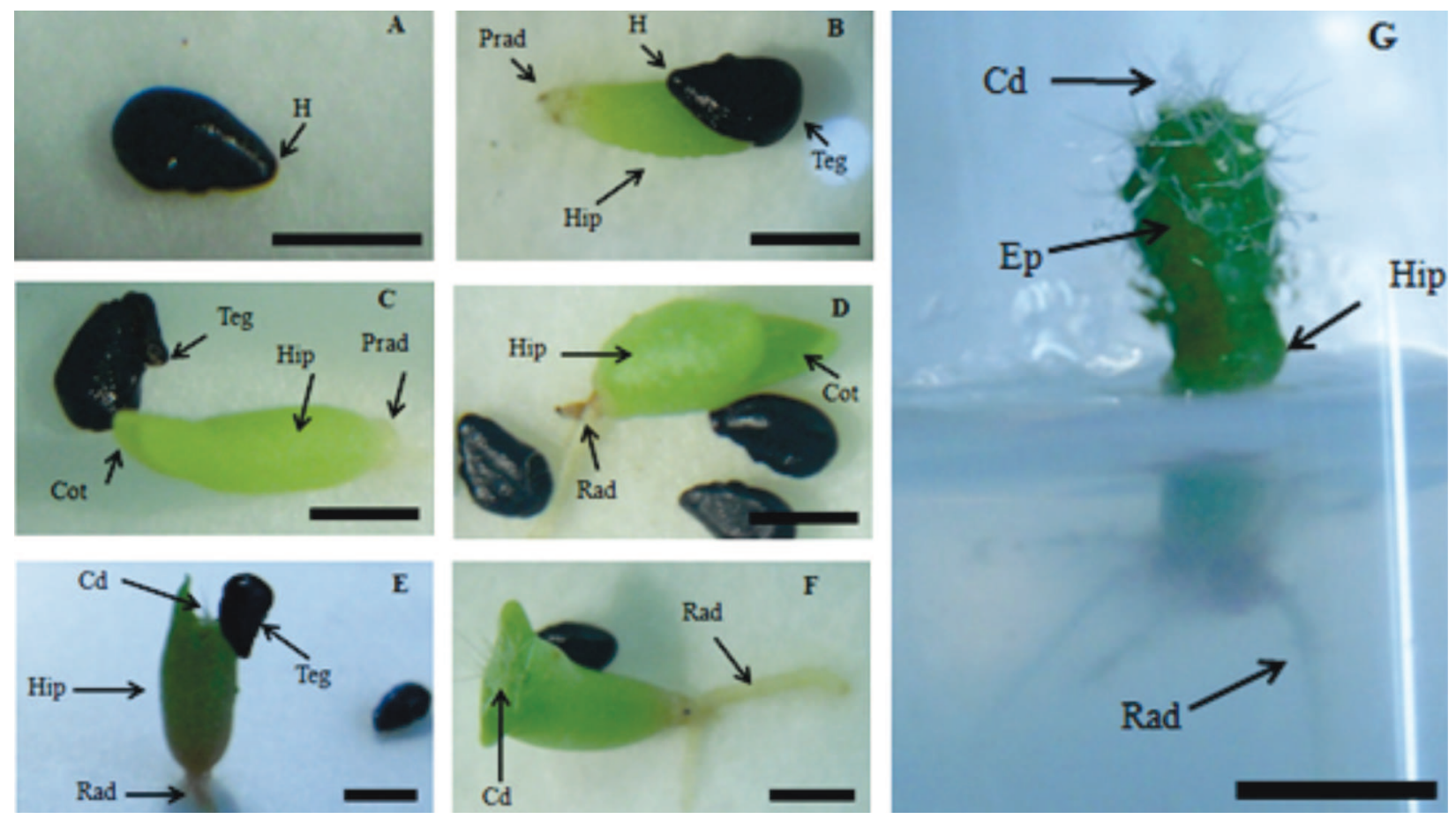

Figura 2. Morfologia do desenvolvimento pós-seminal de plântulas de Pilosocereus aurisetus. Cd: Cerdas; Cot: Cotilédones; Ep: Epicótilo; H: Hilo; Hip: Hipocótilo; Prad: Primórdios radiculares; Rad: Radícula; Teg: Tegumento. Barras: A-F = 1,0 mm e G =1,0cm.

Rev. Ceres, Viçosa, v. 59, n.6, p. 739-744, nov/dez, 2012 
tegumentos e expondo seus dois cotilédones, mas isso não ocorreu para todas as sementes, tendo algumas dessas permanecido com o tegumento aderido ao cotilédone, durante desenvolvimento das plântulas. Espécies como Cephalocereus fluminensis germinam dez dias após a semeadura e mantêm o tegumento aderido na plântula por 24 dias (Salles, 1987).

De sete a nove dias, após o início da protrusão da radícula, inicia-se a expansão dos cotilédones rudimentares, caracteristicamente sésseis, glabros e de coloração verde, como o epicótilo. Sua expansão possibilita a exposição do ápice caulinar, constituído de uma gema apical recoberta de cerdas ou pelos (Figura 2E). A raiz principal apresenta-se alongada, com muitos pelos radiculares absorventes, o colo é ainda mais estreitado e há emissão de grande quantidade de raízes secundárias. Embora não existam relatos sobre a caracterização morfológica de plântulas de cactos, há relatos de que a quantidade de raízes emitidas em plantas micropropagadas do gênero Pilosocereus é elevada, como observado em $P$. robinii (Quiala et al., 2009). Os cotilédones estão completamente expandidos e mais arredondados, após duas semanas do início da germinação, e o ápice da plântula apresenta cerdas bem desenvolvidas, constituindo a aréola que recobre a gema apical (Figura 2F).

Quando plântulas de $P$. aurisetus são cultivadas in vitro, em 60 dias o hipocótilo adquire formato cilíndrico, sendo que o epicótilo é desenvolvido e irregular, evidenciando o início da diferenciação das costelas, quando também é possível verificar a presença de grande quantidade de cerdas e raízes (Figura 2G).

\section{CONCLUSÕES}

Sementes de Pilosocereus aurisetus apresentam germinação in vitro de $90 \%$, após 19 meses de armazenamento, não sendo necessário tratamento para quebra de dormência, nessas condições.

A morfologia do desenvolvimento pós-seminal indicou que a germinação de $P$. aurisetus é do tipo epígea, com hipocótilo de reserva.

A diferenciação e início da formação das costelas dãose aos 60 dias após a germinação, com o desenvolvimento do epicótilo.

\section{REFERÊNCIAS}

Arias S \& Terrazas T (2004) Seed morphology and variation in the genus Pachycereus (Cactaceae). Journal of Plant Research, 117:277-289.

Bregman R \& Bouman F (1983) Seed germination in Cactaceae Botanical Journal of the Linnean Society, 86:325-417.

Brasil (2009) Regras para análise de sementes. Brasília, MAPA/ ACS. 399p.
Flores J, Jurado E \& Jiménez-Bremont JF (2008) Breaking seed dormancy in specially protected Turbinicarpus lophophoroides and Turbinicarpus pseudopectinatus (Cactaceae). Plant Species Biology, 23:43-46.

Guillén S, Benítez J, Martínez-Ramos M \& Casas A (2009) Seed germination of wild, in situ-managed, and cultivated populations of columnar cacti in the Tehuacán-Cuicatlán Valley, Mexico. Journal of Arid Environments, 73:407-413.

Kulkarni MG, Sparg SG \& Van Staden J (2006) Dark conditioning, cold stratification and a smoke-derived compound enhance the germination of Eucomis autumnalis subsp. autumnalis seeds. South African Journal of Botany, 72:157-162.

Landgraf PRC \& Paiva PDO (2009) Produção de mudas para jardim no estado de Minas Gerais. Ciência e Agrotecnologia, 33:127-131

Lenzi M (2008) Biologia reprodutiva de Opuntia monacantha (Willd.) Haw. (Cactaceae) em restingas da ilha de Santa Catarina, sul do Brasil. Tese de doutorado. Universidade Federal de Santa Catarina, Santa Catarina. 95p.

Lessa MA, Paiva PDO, Alves CML \& Resende ML (2009) Application of different fertilizers in substrate for Kalanchoe luciae Raym.-Hamet cultivation. Ciência e Agrotecnologia, 33:950-955.

Melo MFF \& Varela VP (2006) Aspectos morfológicos de frutos, sementes, germinação e plântulas de duas espécies florestais da Amazônia Dinizia excelsa Ducke (Angelim Pedra) e Cedrelinga catenaeformis Ducke (Cedrorana) Leguminosae: Mimosoideae. Revista Brasileira de Sementes, 28:54-62.

Ministério do Meio Ambiente (2008) Lista oficial das espécies da flora brasileira ameaçadas de extinção. Instrução normativa $\mathrm{N}^{\circ}$ 6, de 23/09/2008. Disponível em: http://portal.saude.gov.br/ portal/arquivos/pdf/MMA_IN_N_6.pdf. Acessado em: 06 de novembro de 2008 .

Murashige T \& Skoog F (1962) A revised medium for rapid growth and bioassays with tobacco tissue cultures. Physiologia Plantarum, 15:473-497.

Nunes SCP, Nunes UR, Fonseca PG, Grazziotti PH, Pêgo RG \& Marra LM (2008) Época, local de coleta e armazenamento na qualidade fisiológica da semente de sempre-viva (Syngonanthus elegans (Bong.) Ruhland - Eriocaulaceae). Revista Brasileira de Sementes, 30:32-39.

Olvera-Carrillo Y, Márquez-Guzmán J, Sánchez-Coronado ME, Barradas VL, Rincón E \& Orozco-Segovia A (2009) Effect of burial on the germination of Opuntia tomentosa's (Cactaceae, Opuntioideae) seeds. Journal of Arid Environments, 73:421427.

Olvera-Carrillo Y, Márquez-Guzmán J, Barradas VL, SánchezCoronado ME \& Orozco-Segovia A (2003) Germination of the hard seed coated Opuntia tomentosa S.D., a cacti from the México valley. Journal of Arid Environments, 55:29-42.

Ortega-Baes P \& Godínez-Alvarez H (2006) Global diversity and conservation priorities in the Cactaceae. Biodiversity and Conservation, 15:817-827.

Ortega-Baes P \& Rojas-Aréchiga M (2007) Seed germination of Trichocereus terscheckii (Cactaceae): Light, temperature and gibberellic acid effects. Journal of Arid Environments, 69:169176.

Quiala E, Matos J, Montalvo G, Feria M, Chávez M, Capote A, Pérez N, Barbón R \& Kowalski B (2009) In vitro propagation of Pilosocereus robinii (Lemaire) Byles et Rowley, endemic and endangered cactus. Journal of the Professional Association for Cactus Development, 11:18-25. 
Resende SV, Lima-Brito A \& Santana JRF (2010) Influência do substrato e do enraizamento na aclimatização de Melocactus glaucescens Buining \& Brederoo propagados in vitro. Revista Ceres, 57:803-809.

Reyes-Aguero JA, Aguirre RJR \& Valiente-Banuet A (2006) Reproductive biology of Opuntia: a review. Journal of Arid Environments, 64:549-585.

Rojas-Aréchiga M \& Vázquez-Yanes C (2000) Cactus seed germination: a review. Journal of Arid Environments, 44:85104

Rojas-Aréchiga M, Aguilar KM, Golubov J \& Mandujano MC (2011) Effect of gibberellic acid on germination of seeds of five species of cacti from the Chihuahuan desert, northern Mexico. The Nouthwestern, 55:393-435.
Salles HG (1987) Expressão morfológica de sementes e plântulas I. Cephalocereus fluminensis (Miq) Britton e Rose (Cactaceae). Revista Brasileira Sementes, 9:73-81.

Simão E, Socolowski F \& Takaki M (2007) The epiphytic Cactaceae Hylocereus setaceus (Salm-Dick ex DC.) Ralf Bauer seed germination is controlled by light and temperature. Brazilian Archives of Biology and Technology, 50:655-662.

Soffiatti P \& Angyalossy V (2007) Anatomy of Brazilian Cereae (subfamily Cactoideae, Cactaceae): stem of Arrojadoa Britton \& Rose, Stephanocereus A. Berger and Brasilicereus Backeberg. Acta Botânica Brasilica, 21:813-822.

Yin L, Wang C, Chen Y, Yu C, Cheng Y \& Li W (2009) Cold stratification, light and high seed density enhance the germination of Ottelia alismoides. Aquatic Botany, 90:85-88. 